\title{
Estreptomicetos no controle da meloidoginose em mudas de tomateiro
}

\author{
Carla da Silva Sousa ${ }^{(1)}$, Ana Cristina Fermino Soares ${ }^{(1)}$, Marlon da Silva Garrido $^{(2)}$ \\ e Gabriela Maria Carneiro de Oliveira Almeida ${ }^{(1)}$
}

\begin{abstract}
(1)Universidade Federal do Recôncavo da Bahia (UFRB), Dep. de Fitotecnia, Centro de Ciências Agrárias, Biológicas e Ambientais, Campus da UFRB, s/no, Centro, CEP 44380-000 Cruz das Almas, BA. E-mail: cssagro@yahoo.com.br, acsoares@ufba.br, gueibysmary@hotmail.com (2)Universidade Federal de Pernambuco, Dep. de Energia Nuclear, Avenida Luiz Freire, 1000, CEP 50740-610 Recife, PE. E-mail: garridoms@yahoo.com.br
\end{abstract}

\begin{abstract}
Resumo - Este trabalho teve como objetivo avaliar o efeito de seis isolados de estreptomicetos na mortalidade e eclosão de juvenis de segundo estádio (J2) de Meloidogyne incognita e no controle da meloidoginose em mudas de tomateiro. Foi montado um bioensaio em placas tipo Elisa, sendo adicionados em cada célula, $200 \mu \mathrm{L}$ de metabólitos dos isolados, com $20 \mu \mathrm{L}$ de uma suspensão com 25 juvenis de segundo estádio (J2) de M. incognita. Os metabólitos produzidos por Streptomyces griseus subsp. griseus causaram 98,2\% de mortalidade dos J2 de M. incognita. Em outro bioensaio, foram adicionados $3 \mathrm{~mL}$ dos metabólitos em frascos de vidro, com $100 \mu \mathrm{L}$ da suspensão contendo 25 ovos de M. incognita. O isolado N0035 de Streptomyces proporcionou 98,8\% de inibição na eclosão de J2 de M. incognita. Num terceiro bioensaio, o substrato de produção de mudas foi infestado com suspensão de estreptomicetos e incubado por 30 dias. Quinze dias depois da germinação das sementes do tomateiro, foi realizada a inoculação com $2.000 \mathrm{~J} 2$ por planta. Verificou-se a redução de $68 \%$ no número de galhas por grama de raiz e de $76,8 \%$ na massa de ovos por grama de raiz, nas mudas produzidas no substrato infestado e incubado com Streptomyces griseus subsp. griseus, quando comparado com a testemunha.
\end{abstract}

Termos para indexação: Meloidogyne incognita, Lycopersicon esculentum, Streptomyces, actinomicetos, nematóide-das-galhas, biocontrole.

\section{Streptomycetes in the control of Meloidogyne incognita in tomato plants}

\begin{abstract}
This work aimed to evaluate the effect of six streptomycete isolates on mortality, hatching, and control of Meloidogyne incognita on tomato seedlings. An assay was conducted in Elisa plates, with the addition of $200 \mu \mathrm{L}$ of the streptomycete metabolites, along with $20 \mu \mathrm{L}$ of suspension containing 25 second stage juveniles (J2) of M. incognita. The metabolites produced by Streptomyces griseus subsp. griseus caused mortality of $98.2 \%$ on M. incognita. A second assay was conducted with $3 \mathrm{~mL}$ of streptomycete metabolites and 25 eggs of M. incognita. The isolate N0035 of Streptomyces caused inhibition of $98.8 \%$ on hatching. In a third assay, potting mix was infested with suspension of the streptomycetes isolates and incubated for 30 days. Fifteen days after germination, tomato seedlings were inoculated with a suspension containing 2,000 J2 of M. incognita. Reductions of $68 \%$ in the number of galls per gram of roots and of $76.8 \%$ in the egg mass per gram of roots were observed on tomato seedlings grown in the potting mix inoculated with Streptomyces griseus subsp. griseus, compared to the control.
\end{abstract}

Index terms: Meloidogyne incognita, Lycopersicon esculentum, Streptomyces, actinomycetes, root knot nematode, biocontrol.

\section{Introdução}

Em quase todas as regiões do mundo, um dos problemas fitossanitários mais prejudiciais ao tomateiro é a meloidoginose. Essa doença é causada por nematóides do gênero Meloidogyne spp., conhecidos como nematóidesde-galhas, devido ao sintoma característico de formação de galhas nas raízes da planta. A formação de galhas nas raízes do tomateiro (Lycopersicon esculentum Mill) impede a absorção de água e nutrientes do solo, provocando deficiência mineral e perda de produtividade da ordem de 25 a 85\% (Lopes \& Santos, 1994).

Nematicidas de solo, além de apresentar elevado custo, são prejudiciais à saúde humana, animal e ao meio ambiente, e são pouco eficientes no controle da meloidoginose em hortaliças (Filgueira, 2000). Assim, o controle biológico tem-se apresentado como alternativa viável para o manejo de fitonematóides, por minimizar o 
dano ambiental e ser mais vantajoso economicamente, comparado aos métodos químicos convencionais (Coimbra \& Campos, 2005).

Os actinomicetos constituem um importante grupo de bactérias, comumente isoladas do solo, pertencentes à classe Actinobacteria, conhecidos por sua ampla produção de metabólitos secundários, entre eles os antibióticos, enzimas extracelulares e inibidores enzimáticos, com aplicações na Medicina, Agricultura e Veterinária. O gênero Streptomyces spp. tem sido o mais estudado com relação ao controle biológico de fitopatógenos, em razão da diversidade de metabólitos secundários produzidos por esse gênero e da capacidade competitiva por substratos (Inbar et al., 2005).

Estudos têm demonstrado o potencial dos actinomicetos como agentes de controle biológico dos nematóides M. incognita, Rotylenchulus reniformis e Pratylenchus penetrans (Jonathan et al., 2000). Streptomyces costaricanus reduziu o número de galhas em raízes de pimenteira plantada em solo naturalmente infestado com $M$. incognita, bem como a população de P. penetrans em raízes de morango (Fragaria vesca) e a população de $R$. reniformis em tomateiro (Lycopersicon esculentum Mill.) e pimenteira (Capsicum sp.) (Dicklow et al., 1993). Coimbra et al. (2004) testando isolados de actinomicetos obtidos da rizosfera de diferentes culturas, visando ao controle de $M$. javanica em mudas de tomateiro, observaram redução de 61\% e 69\% nos números de galhas e de massas de ovos, respectivamente, quando comparados com a testemunha.

O objetivo deste trabalho foi avaliar o efeito de seis isolados de estreptomicetos na eclosão e mortalidade de juvenis do segundo estádio (J2) de $M$. incognita, e no controle da meloidoginose em mudas de tomateiro.

\section{Material e Métodos}

Seis isolados de estreptomicetos foram avaliados: S. thermotolerans, S. griseus subsp. griseus, Streptomyces sp. N0035, S. purpuraceans e dois isolados de Streptomyces sp., codificados como AC-29, AC-92, AC-95, AC-103, AC-147 e AC-26, respectivamente, provenientes da coleção do Laboratório de Fitopatologia e Microbiologia Agrícola do Centro de Ciências Agrárias, Biológicas e Ambientais da Universidade Federal do Recôncavo da Bahia, e previamente selecionados como potenciais agentes de promoção de crescimento. Os isolados foram multiplicados em meio de cultura sólido AGS (Porter et al., 1960).
As culturas foram incubadas em câmara de crescimento tipo BOD, a $28^{\circ} \mathrm{C}$, por dez dias. Depois da incubação, foram adicionados $10 \mathrm{~mL}$ de água destilada esterilizada em cada placa de Petri, deixando-as em repouso durante 24 horas. Posteriormente, a suspensão obtida foi centrifugada a $12.000 \mathrm{rpm}$, durante $15 \mathrm{~min}$ e, em seguida, submetida à filtragem em membrana de nitrocelulose Millipore $(0,22 \mu \mathrm{m})$, para a obtenção de um filtrado livre de células de estreptomicetos, apenas com os metabólitos produzidos por esses microrganismos. A suspensão com os metabólitos foi transferida para frascos de vidro, esterilizados e armazenados no congelador a $4^{\circ} \mathrm{C}$.

Na obtenção dos ovos, raízes de tomateiro cultivar Santa Clara, cultivado em casa de vegetação, com galhas e massas de ovos, foram lavadas com água potável e trituradas em liquidificador por 20 s com solução de hipoclorito de sódio a 0,5\%, seguindo-se a técnica de Hussey \& Barker (1973), modificada por Boneti \& Ferraz (1981). Os resíduos das raízes e impurezas foram separados dos ovos pela técnica de Coolen \& D’Herde (1972). Quanto à desinfestação dos ovos, em câmara de fluxo laminar, a suspensão foi passada numa peneira de 400 mesh, previamente desinfestada com álcool $70 \%$. Os ovos retidos na peneira foram lavados três vezes com água destilada esterilizada. Em seguida, foram colocados numa solução de hipoclorito de sódio a $0,5 \%$ durante um minuto e lavados com água destilada esterilizada por quatro vezes, sendo posteriormente transferidos para um erlenmeyer esterilizado, e, em seguida, armazenados em geladeira.

Na obtenção dos J2, raízes de tomateiro da cultivar Santa Clara, infestadas com $M$. incognita, cultivados em casa de vegetação, foram lavadas com água potável e trituradas em liquidificador por 20 s com solução de hipoclorito de sódio a $0,5 \%$, seguindo-se a técnica de Hussey \& Barker (1973), modificada por Boneti \& Ferraz (1981). Em seguida, a suspensão de raízes trituradas foi transferida para um conjunto de peneiras, constituído por uma peneira superior de 60 mesh e uma peneira inferior de 400 mesh. O material retido na peneira inferior foi transferido para câmara de eclosão, montada numa placa de Petri com tela de 35 mesh e papel toalha poroso. Os J2 eclodidos nas primeiras 24 horas foram descartados. Nos ensaios utilizaram-se apenas J2 eclodidos nas 24 horas seguintes. Quanto à desinfestação dos J2, a suspensão obtida na câmara de eclosão foi transferida para uma peneira de 400 mesh, 
na qual os J2 ficaram retidos. A peneira com os J2 foi imersa em solução de hipoclorito de sódio a 0,5\% durante $1 \mathrm{~min}$, seguido de quatro lavagens com água destilada esterilizada. Para confirmação da espécie, foi realizado o corte na região perineal das fêmeas adultas, conforme método proposto por Taylor \& Sasser (1978).

A fim de avaliar o efeito dos metabólitos produzidos pelos seis isolados de estreptomicetos sobre os J2 de $M$. incognita, foi montado um bioensaio em placas tipo Elisa esterilizadas, em delineamento inteiramente casualizado, com oito repetições. Em cada célula da placa, foram adicionados $200 \mu \mathrm{L}$ dos metabólitos produzidos pelos isolados de estreptomicetos, com $20 \mu \mathrm{L}$ de uma suspensão aquosa contendo $25 \mathrm{~J} 2$ de M. incognita. A testemunha foi constituída dos J2 em água esterilizada. As placas foram vedadas com parafilme e acondicionadas em câmara de crescimento tipo BOD, a $28^{\circ} \mathrm{C}$. Após 24 horas de incubação realizouse a contagem dos nematóides móveis e imóveis, com auxílio de microscópio de objetiva invertida. Em seguida, os nematóides foram retirados da suspensão de metabólito, colocados em água e mantidos por mais 24 horas em câmara de crescimento tipo BOD, a $28^{\circ} \mathrm{C}$. Foram considerados mortos os nematóides que, depois desse período em água, não recuperaram a mobilidade. Os dados foram transformados em arc sen $(\mathrm{x} / 100)^{0,5}$, e a comparação de médias foi feita pelo teste de Tukey, a $5 \%$ de probabilidade, utilizando-se o programa SISVAR 4.3 (Ferreira, 2000).

A fim de avaliar o efeito dos metabólitos produzidos pelos seis isolados de estreptomicetos na eclosão de J2 de $M$. incognita, foi montado um segundo bioensaio, em delineamento inteiramente casualizado, com quatro repetições. Em frascos de vidro esterilizados, foram colocados $3 \mathrm{~mL}$ da suspensão de metabólitos, produzidos pelos isolados de estreptomicetos, com $100 \mu \mathrm{L}$ de uma suspensão contendo 25 ovos do nematóide. Como testemunha, a suspensão de ovos foi colocada em frascos de vidro contendo água esterilizada. Os frascos foram incubados a $28^{\circ} \mathrm{C}$ em câmara de crescimento tipo BOD. Quinze dias depois da incubação, foi realizada a contagem do número de J2 eclodidos em câmara de Peters com auxílio de um microscópio óptico. Com base na concentração de ovos da suspensão inicial e o número de J2 eclodidos, calculou-se a porcentagem de eclosão de ovos. Os dados foram transformados em arc sen $(\mathrm{x} / 100)^{0,5}$, e a comparação de médias foi feita pelo teste de Tukey, a $5 \%$ de probabilidade, com o programa SISVAR 4.3 (Ferreira, 2000).
Para avaliar o efeito dos estreptomicetos no controle da meloidoginose, em mudas de tomateiro, um experimento foi instalado em delineamento experimental em blocos ao acaso com 15 repetições. Inicialmente, os estreptomicetos foram cultivados em arroz autoclavado a $28 \pm 2^{\circ} \mathrm{C}$ por 12 dias (Soares et al., 2005). O arroz colonizado pelos estreptomicetos foi lavado com água destilada e a concentração da suspensão foi ajustada para densidade ótica de $\mathrm{A}_{560}=0,4$ em espectrofotômetro UV (modelo Bell 1105). A infestação foi feita com $20 \mathrm{~mL}$ da suspensão para cada $400 \mathrm{~cm}^{3}$ de substrato, e incubado durante 43 dias, à temperatura ambiente $\left(28 \pm 2^{\circ} \mathrm{C}\right)$, em sacos de polietileno. A umidade do substrato foi mantida com a adição de água potável. A semeadura foi realizada, colocando-se três sementes de tomateiro cv. Santa Clara, sendo realizado o desbaste, uma semana depois da germinação, deixando-se uma planta por saco.

A suspensão de nematóides foi quantificada em câmara de Peters, com auxílio do microscópio de objetiva invertida. Quinze dias depois da germinação das sementes de tomateiro foi realizada a inoculação das mudas com cerca de $2000 \mathrm{~J} 2$ por planta, por meio de orifícios no substrato, e colocando o inóculo em contato com as raízes, com o auxilio de uma micropipeta de $1 \mathrm{~mL}$. Quarenta dias depois da inoculação com $M$. incognita, foi realizada coleta das plantas, avaliando-se a altura e diâmetro do caule à altura dos cotilédones. Em seguida, separou-se a parte aérea das plantas, que foi lavada em água corrente e, em seguida, colocada para secar em estufa com ventilação forçada a $65^{\circ} \mathrm{C}$, até atingir massa constante. Na contagem do número de massa de ovos e galhas, as raízes foram coloridas, por imersão em solução de fucsina ácida a 0,15\%, durante 20 min.

Para avaliar a capacidade in vitro dos isolados de estreptomicetos em colonizar o sistema radicular das mudas de tomateiro, sementes de tomate da cultivar Santa Clara foram desinfestadas por meio de imersão nas soluções de álcool 70\% (3 min)e hipoclorito de sódio 1\% (1 min), seguida de seis lavagens consecutivas em água destilada esterilizada. Depois de desinfestadas, as sementes foram transferidas, com auxílio de uma pinça estéril, para tubos de ensaio, contendo meio de cultura ágar-água com 0,6\% de ágar. Os tubos foram mantidos em câmara de crescimento sem luz, a $28^{\circ} \mathrm{C}$, até a emissão da radícula (período de 3 a 4 dias). Depois da emissão da radícula, com auxílio de uma alça de platina, realizou-se a raspagem dos estreptomicetos e os esporos foram colocados próximo à radícula. Os tubos de ensaio foram mantidos 
à temperatura e luminosidade ambiente, sendo diariamente observada a colonização radicular. A produção de lipase pelos estreptomicetos foi avaliada no meio Sierra (1957), usando Tween 80 como substrato. A atividade quitinolítica dos estreptomicetos foi determinada de acordo com o método proposto por Renwick et al. (1991), utilizando quitina coloidal como substrato.

\section{Resultados e Discussão}

Os isolados Streptomyces sp. (AC-26), Streptomyces griseus subsp. griseus (AC-92) e Streptomyces N0035 (AC-95) aumentaram a mortalidade dos J2, quando comparados com a testemunha. Streptomyces griseus subsp. griseus (AC-92) proporcionou 98,2\% de mortalidade dos J2, quando comparado aos $27,3 \%$ observados na testemunha (Tabela 1), destacando-se como o isolado mais eficiente no controle de $M$. incognita in vitro. Os metabólitos produzidos pelos isolados Streptomyces N0035 (AC-95) e Streptomyces sp. (AC-26) causaram 50 e 59\% de mortalidade dos J2, diferindo estatisticamente da testemunha e do isolado AC-92. Com relação aos isolados Streptomyces purpuraceans (AC-103) e Streptomyces thermotolerans (AC-29), obteve-se 37\% e 39\% de mortalidade dos J2, respectivamente, não diferindo da testemunha.

Coimbra \& Campos (2005), ao avaliar o efeito de exsudatos de actinomicetos na motilidade e mortalidade de J2 de M. javanica, verificaram que seis isolados entre os 37 testados, tinham efeito nematicida, observando valores de mortalidade entre 19 e 100\%. A supressão da motilidade de J2 de $M$. incognita por filtrados de culturas de isolados de Streptomyces sp. foi observada por Chubachi et al. (2002). O efeito dos metabólitos secundários na mortalidade dos J2 variou com as espécies de estreptomicetos, sugerindo que substâncias diversas, com diferentes graus de

Tabela 1. Efeito dos metabólitos produzidos pelos isolados de estreptomicetos na mortalidade e eclosão de juvenis de Meloidogyne incognita ${ }^{(1)}$.

\begin{tabular}{lcc}
\hline Isolado de estreptomiceto & Mortalidade (\%) & Eclosão (\%) \\
\hline Testemunha (água) & $27,3 \mathrm{~d}$ & $76,3 \mathrm{~b}$ \\
S. griseus subsp. griseus (AC-92) & $98,2 \mathrm{a}$ & $-(2)$ \\
Streptomyces sp. (AC-26) & $59,2 \mathrm{~b}$ & - \\
Streptomyces sp. N0035 (AC-95) & $50,0 \mathrm{bc}$ & $1,2 \mathrm{a}$ \\
S. thermotolerans (AC-29) & $39,3 \mathrm{~cd}$ & $96,3 \mathrm{~b}$ \\
S. purpuraceans (AC-103) & $37,0 \mathrm{~cd}$ & $68,3 \mathrm{~b}$ \\
\hline
\end{tabular}

(1)Letras iguais na coluna não diferem entre si pelo teste de Tukey, a 5\% de probabilidade. ${ }^{(2)}$ Material não avaliado devido à contaminação. toxicidade aos nematóides, são produzidas pelos estreptomicetos avaliados.

Além da diferença intrínseca que ocorre entre as espécies, outras características do meio de crescimento como $\mathrm{pH}$, temperatura e disponibilidade de nutrientes, podem interferir tanto na quantidade quanto na composição dos metabólitos produzidos (Gava, 1998), o que pode explicar, em parte, a diversidade metabólica e, conseqüentemente, o diferente grau de mortalidade proporcionado pelos isolados de estreptomicetos testados. Walker et al. (1966), ao testar filtrados de quatro isolados de Streptomyces sobre juvenis e adultos de Pratylenchus penetrans, observaram que ocorreu $40 \%$ de mortalidade, quando as culturas foram incubadas em temperaturas de 5,10 e $15^{\circ} \mathrm{C}$, e $15 \%$ de mortalidade, quando os filtrados foram obtidos de culturas incubadas à temperatura de $25^{\circ} \mathrm{C}$.

A concentração da suspensão de metabólitos e o período de exposição dos nematóides também podem influenciar a taxa de mortalidade dos J2. A imobilidade e a mortalidade de $\mathrm{J} 2$ de $M$. javanica aumentaram em todos os filtrados bacterianos testados por Naves et al. (2004), quando se aumentou o período de exposição de 24 para 48 horas. Esses autores concluíram que o somatório dos efeitos de substâncias diferentes exige tempo para sua expressão e, portanto, o período de avaliação de 48 horas seria mais apropriado. Costa et al. (2001) verificaram, com o filtrado do fungo Paecilomyces lilacinus, que, ao passar da diluição de 1:2 para 1:3 (filtrado:água), houve queda na porcentagem de J2 de $M$. incognita mortos, passando de aproximadamente $95 \%$ para $30 \%$. Park et al. (2002) observaram porcentagens de redução da mobilidade de Caenorhabiditis elegans entre 50 e 90\%, em períodos de 3 e 6 horas de incubação, respectivamente, quando colocados diretamente na colônia de Streptoverticillium albireticuli, cultivado em placas de Petri por sete dias no meio FMEA.

Além do efeito na mortalidade dos J2, os metabólitos produzidos pelo isolado Streptomyces N0035 (AC-95) também demonstraram efeito ovicida, inibindo a eclosão dos J2 de M. incognita em 98,8\% (Tabela 1). Antibióticos e toxinas produzidos por microorganismos podem ser absorvidos pelos ovos dos nematóides, matando as células, impedindo o desenvolvimento embrionário e formação do juvenil (Freitas, 2005). Porsua vez, os metabólitos produzidos pelos isolados Streptomyces thermotolerans (AC-29) e Streptomyces purpuraceans (AC-103) não demonstraram efeito significativo na mortalidade e na 
inibição da eclosão dos J2 de M. incognita. Estes resultados indicam que os metabólitos produzidos por estes estreptomicetos, nas condições de cultivo analisadas, não apresentam efeito nematicida ou necessitam ser avaliados em concentrações mais elevadas ou períodos mais longos de contato com os nematóides, devido ao possível baixo grau de toxicidade. Quantos aos isolados AC-26 e AC-92, em virtude da contaminação por bactérias, não foi possível avaliar o efeito ovicida dos metabólitos.

De acordo com os aspectos morfológicos da região perineal das fêmeas adultas, a espécie foi identificada como M. incognita. No teste in vitro, observou-se que isolados de estreptomicetos, em especial Streptomyces griseus subsp. griseus (AC-92), produziram metabólitos com efeito nematicida, causando a mortalidade dos J2. Este mesmo isolado causou significativa redução no número de galhas (68\%) e massa de ovos por grama de raiz $(76,8 \%)$ nas mudas de tomateiro (Tabela 2 ). O desenvolvimento do nematóide no interior das raízes do tomateiro pode ter sido afetado pelos isolados Streptomyces griseus subsp. griseus (AC-92), Streptomyces N0035 (AC-95) Streptomyces purpuraceans (AC-103), nos quais foram observadas 13,2 , 14,3 e 14,5 galhas por grama de raiz, respectivamente, enquanto mudas do tratamento-testemunha apresentaram média de 41,2 galhas por grama de raiz, correspondendo a uma redução de 68,0, 65,3 e 64,8 em relação à testemunha (Tabela 2$)$.

O substrato foi infestado e incubado por 43 dias antes do plantio com os estreptomicetos, e, provavelmente, nesse período, esses microrganismos colonizaram e produziram metabólitos secundários no substrato que causaram a mortalidade e inibiram a eclosão dos J2,

Tabela 2. Número de galhas e número de massa de ovos por grama de raiz, das mudas de tomateiro cultivadas em substrato infestado e incubado com os isolados de estreptomicetos ${ }^{(1)}$.

\begin{tabular}{|c|c|c|c|c|}
\hline \multirow[t]{2}{*}{ Isolado de estreptomiceto } & \multicolumn{2}{|c|}{$\begin{array}{c}\text { Galhas por grama } \\
\text { de raiz }\end{array}$} & \multicolumn{2}{|c|}{$\begin{array}{c}\text { Massa de ovos } \\
\text { por grama de raiz }\end{array}$} \\
\hline & Número & $\begin{array}{l}\text { Redução } \\
(\%)\end{array}$ & Número & $\begin{array}{c}\text { Redução } \\
(\%)\end{array}$ \\
\hline Testemunha & $41,2 \mathrm{a}$ & - & $9,5 \mathrm{a}$ & - \\
\hline Streptomyces sp. (AC-26) & $21,1 \mathrm{ab}$ & 48,8 & $4,4 b$ & 53,7 \\
\hline S. thermotolerans (AC-29) & $21,4 \mathrm{ab}$ & 48,1 & $2,8 \mathrm{~b}$ & 70,5 \\
\hline S. griseus subsp. griseus (AC-92) & $13,2 b$ & 68,0 & $2,2 \mathrm{c}$ & 76,8 \\
\hline Streptomyces sp. N0035 (AC-95) & $14,3 b$ & 65,3 & $2,5 b$ & 73,7 \\
\hline S. purpuraceans (AC-103) & $14,5 b$ & 64,8 & $3,0 \mathrm{~b}$ & 68,4 \\
\hline Streptomyces sp. (AC-147) & $17,9 \mathrm{ab}$ & 56,6 & $4,2 \mathrm{~b}$ & 55,8 \\
\hline
\end{tabular}

reduzindo a infectividade nas raízes do tomateiro. A produção de metabólitos secundários no substrato e na rizosfera da planta pode causar a imobilidade e mortalidade do nematóide, antes da penetração nas raízes, reduzindo a infectividade e, conseqüentemente, o número de galhas, em razão do baixo número de nematóides que infectam a planta. Além disso, as rizobactérias ou seus metabólitos podem ser absorvidos pela planta e desencadear reação de hipersensibilidade nas células gigantes ou síncitos que, quando anormais em forma, tamanho e conteúdo, impedem os nematóides de atingir a fase adulta, e as fêmeas não conseguem reservas suficientes para produzir ovos (Freitas, 2005).

Metabólitos produzidos pelo isolado Streptomyces purpuraceans (AC-103) não demonstraram efeito nematicida significativo in vitro, contudo, as mudas de tomateiro, produzidas no substrato infestado e incubado com esse isolado, apresentaram redução significativa no número de galhas e de massa de ovos nas raízes, sugerindo que podem ocorrer outros mecanismos de biocontrole, a exemplo da indução de resistência (Samac \& Kinkel, 2001), além da produção de metabólitos. As condições do meio de crescimento também afetam a produção em termos de quantidade e tipo de metabolitos pelos actinomicetos, ocorrendo muitas vezes resultado, na planta, diferente dos observados in vitro. Jonathan et al. (2000) aplicaram isolados de actinomicetos no solo infestado por $M$. incognita, plantando, em seguida, mudas de tomateiro e bananeira. Doze semanas depois do plantio, constataram, em ambas as espécies, redução dos números de galhas e de ovos, bem como promoção do crescimento vegetativo, comparado com a testemunha. Krechel et al. (2002), depois de testar isolados de actinomicetos do gênero Streptomyces, obtidos da rizosfera da batateira, visando ao controle de $M$. incognita em casa de vegetação, observaram redução no número de galhas entre 50 e $85 \%$ e redução no número de massas de ovos entre 40 e $100 \%$, quando comparados com a testemunha.

Com relação à massa de ovos, embora todos os isolados de estreptomicetos tenham demonstrado efeito nematicida, diferindo estatisticamente da testemunha, destacaram-se os isolados Streptomyces griseus subsp. griseus (AC-92) e Streptomyces N0035 (AC-95), os quais proporcionaram redução de 76,8 e $73,7 \%$, respectivamente, quando comparados à testemunha. Trabalhos têm demonstrado a eficácia dos actinomicetos, principalmente os do gênero Streptomyces, na redução da população de fitonematóides. A infestação prévia do solo com trigo 
pré-incorporado com Streptomyces costaricanus, cultivado em meio líquido, também reduziu a população de Radopholus similis e de Helicotylenchus multicinctus (Esnard et al., 1998).

A orientação e a migração de fitonematóides para raízes dependem de vários fatores, entre eles, a natureza dos exsudatos radiculares. Os microrganismos, por sua vez, colonizam o sistema radicular e afetam a composição química dos exsudatos liberados (Melo, 1998). A transformação dos exsudatos radiculares em subprodutos pode fazer com que o nematóide não reconheça o estímulo quimiotrópico e continue movimentando-se no solo até esgotar suas reservas de energia, vindo a morrer sem penetrar na raiz (Freitas, 2005). O tratamento das raízes de soja com suspensão de Bacillus subtilis reduziu a infectividade por Heterodera glycines (Araújo et al., 2002). Esses autores citam que o efeito se deve à degradação bacteriana dos compostos que compõem os exsudatos que estimulam a migração dos juvenis recém-eclodidos até a raiz.

Outro possível mecanismo de biocontrole consiste no parasitismo pelos estreptomicetos, por meio da produção de enzimas como proteases, quitinases e lipases que atuam na destruição da cutícula dos nematóides (Park et al., 2002). Todos os isolados de estreptomicetos testados demonstraram produzir a enzima lipase e, com exceção do isolado Streptomyces griseus subsp. griseus (AC-92), apresentaram capacidade de produção de quitinase (Tabela 3). Miller

Tabela 3. Produção de quitinase, lipase e capacidade de colonização radicular in vitro de mudas de tomateiro pelos isolados de estreptomicetos.

\begin{tabular}{lcccc}
\hline Isolado de estreptomiceto & \multicolumn{2}{c}{$\begin{array}{c}\text { Enzimas } \\
\text { extracelulares }\end{array}$} & \multirow{2}{*}{$\begin{array}{c}\text { Colonização } \\
\text { radicular }\end{array}$} \\
\cline { 2 - 3 } & Lipase & Quitinase & \\
\hline Streptomyces sp. (AC-26) & + & + & + \\
S. thermotolerans (AC-29) & + & + & + \\
S. griseus subp. griseus (AC-92) & + & - & + \\
Streptomyces sp. N0035 (AC-95) & + & + & + \\
S. purpuraceans (AC-103) & + & + & + \\
Streptomyces sp. (AC-147) & + & + & + \\
\hline
\end{tabular}

\& Sands (1977), ao testar os efeitos in vitro das enzimas protease, lipase e quitinase sobre Tylenchorhynchus dubius, observaram que, depois de 24 horas, houve modificações estruturais na cutícula do nematóide, devido a provável degradação enzimática.

A infestação e a incubação do substrato orgânico com os estreptomicetos avaliados promoveram aumento no crescimento das mudas de tomateiro. Foi observado incremento de $22,8 \%$ na altura das mudas de tomateiro produzidas no substrato inoculado e incubado com o isolado AC-29, quando comparado com a testemunha (Tabela 4). Um aumento de 18,4\% foi observado no diâmetro do caule das plantas produzidas no substrato incubado com o isolado Streptomyces sp. (AC-147).

Com relação ao acúmulo de matéria seca na parte aérea das plantas, observou-se incremento significativo de 43,9\% nas mudas de tomateiro produzidas no substrato incubado com o isolado Streptomyces sp. (AC-26). Houve aumento de $64,9 \%$ na matéria seca das raízes das mudas produzidas no substrato inoculado e incubado com o isolado Streptomyces sp. N0095 (AC-95).

A promoção de crescimento por actinomicetos está associada à capacidade desses microrganismos em colonizar o sistema radicular das plantas e produzir substâncias promotoras de crescimento e enzimas que atuam na mineralização da matéria orgânica, disponibilizando nutrientes para as plantas (Inbar et al., 2005). O maior crescimento das mudas de tomateiro, produzidas em substratos infestados com estreptomicetos também pode ser atribuído ao efeito nematicida dos metabólitos produzidos pelos isolados, a exemplo do AC92, que revelou redução no número de galhas e massa de ovos, com maior acúmulo de matéria seca da parte áerea e das raízes. Os actinomicetos apresentam capacidade de biocontrole de fitopatógenos, por meio de

Tabela 4. Altura, diâmetro do caule, matéria seca da parte aérea (MSPA) e matéria fresca das raízes (MFR) das mudas de tomateiro cultivadas em substrato infestado e incubado com os isolados de estreptomicetos ${ }^{(1)}$.

\begin{tabular}{|c|c|c|c|c|}
\hline \multirow[t]{2}{*}{ Isolado de estreptomiceto } & Altura & Diâmetro & MSPA & MFR \\
\hline & \multicolumn{2}{|c|}{---------------- $(\mathrm{cm})$--------------- } & --------- & ----------- \\
\hline Testemunha & $57,49 b$ & $0,385 b$ & $4,15 b$ & $7,81 \mathrm{~d}$ \\
\hline Streptomyces sp. (AC-26) & $65,03 \mathrm{ab}$ & $0,433 \mathrm{ab}$ & $5,97 \mathrm{a}$ & $9,72 \mathrm{~cd}$ \\
\hline S. thermotolerans (AC-29) & $70,57 \mathrm{a}$ & $0,412 \mathrm{ab}$ & $5,23 \mathrm{ab}$ & $9,05 \mathrm{~cd}$ \\
\hline S. griseus subsp. griseus (AC-92) & $64,81 \mathrm{ab}$ & $0,421 \mathrm{ab}$ & $5,92 \mathrm{a}$ & $12,52 \mathrm{ab}$ \\
\hline Streptomyces sp. N0035 (AC-95) & $64,52 \mathrm{ab}$ & $0,424 \mathrm{ab}$ & $5,70 \mathrm{a}$ & $12,95 \mathrm{a}$ \\
\hline S. purpuraceans (AC-103) & $62,73 \mathrm{ab}$ & $0,396 b$ & $5,44 a$ & $10,49 b c$ \\
\hline Streptomyces sp. (AG147) & $66,64 \mathrm{ab}$ & $0,456 \mathrm{a}$ & $5,56 \mathrm{a}$ & $12,00 \mathrm{ab}$ \\
\hline
\end{tabular}

${ }^{(1)}$ Letras iguais na coluna não diferem entre si pelo teste de Tukey, a 5\% de probabilidade. 
mecanismos como produção de antibióticos, enzimas líticas e indução a resistência (El-Abyad et al., 1993; Samac \& Kinkel, 2001).

\section{Conclusão}

Os isolados de actinomicetos utilizados apresentam potencial para controle de Meloidogyne incognita em mudas de tomateiro.

\section{Agradecimentos}

À Fapesb, pelo apoio financeiro ao projeto e pela bolsa Pibic/Junior; à Capes, pela concessão da bolsa.

\section{Referências}

ARAÚJO, F.F. de; SILVA, J.F.V.; ARAÚJO, A.S.F. de. Influência de Bacillus subtilis na eclosão, orientação e infecção de Heterodera glycines em soja. Ciência Rural, v.32, p.197-203, 2002.

BONETTI, J.I.S.; FERRAZ, S. Modificações no método Hussey \& Barker para extração de ovos de Meloidogyne exigua, em raízes de cafeeiro. Fitopatologia Brasileira, v.6, p.533, 1981.

CHUBACHI, K.; FURUKAWA, M.; FUKUDA, S.; MATSUMURA, S.; YANAGISAWA, T.; ITAGAWA, H.; SHIMIZU, T.; NAKAGAWA, A. Suppressive effects of antinematodal Streptomyces spp. on root-knot nematodes of cucumbers caused by Meloidogyne incognita. Biocontrol Science, v.7, p.25-30, 2002.

COIMBRA, J.L.; CAMPOS, V.P. Efeito de exsudatos de colônias e de filtrados de culturas de actinomicetos na eclosão, motilidade e mortalidade de juvenis do segundo estádio de $M$. javanica. Fitopatologia Brasileira, v.30, p.232-238, 2005.

COIMBRA, J.L.; CAMPOS, V.P.; SOUZA, R.M. Efeito antagônico de actinomicetos isolados de diferentes culturas na formação de galhas e na reprodução de $M$. javanica em tomateiro. Nematologia Brasileira, v.28, p.231-234, 2004.

COOLEN, W.A.; D'HERDE, C.J. A method for the quantitative extraction of nematodes from plant tissue. Ghent: State Agriculture Research Centre, 1972. 77p.

COSTA, M.J.N.; CAMPOS, V.P.; PFENNING, L.H.; OLIVEIRA, D.F. Toxicidade de filtrados a $M$. incognita. Fitopatologia Brasileira, v.26, p.749-755, 2001.

DICKLOW, M.B.; ACOSTA, N.; ZUCKERMAN, B.M. A novel Streptomyces species for controlling plant-parasitic nematodes. Journal of Chemical Ecology, v.19, p.159-173, 1993.

EL-ABYAD, M.S.; EL-SAYED, M.A.; EL-SHANSHOURY, A.R. Towards the biological control of fungal and bacteria disease of tomato using antagonistic Streptomyces spp. Plant and Soil, v.149, p.185195, 1993.

ESNARD, J.; MARBAN-MENDONZA, N.; ZUCKERMAN, B. Effects of three microbial broth cultures and a organic amendment on growth and populations of free living and plant-parasitic nematodes on banana. European Journal of Plant Pathology, v.104, p.457463, 1998.

FERREIRA, D.F. Análises estatísticas por meio do Sisvar para Windows versão 4.0. In: REUNIÃO ANUAL DA REGIÃO BRASILEIRA DA SOCIEDADE INTERNACIONAL DE BIOMETRIA, 45., 2000, São Carlos. Anais. São Carlos: UFSCar, 2000. p.255-258.

FILGUEIRA, F.A.R. Manual de oleicultura: cultura e comercialização de hortaliças. São Paulo: Ed. Agronômica Ceres, 2000. v.2, 357p.

FREITAS, L.G. Rizobactérias versus nematóides. Disponível em: $<$ http://www.ufv.br/dfp/lab/nematologia/rizo.pdf>. Acesso em: jan. 2005.

GAVA, C.A.T. Seleção de estreptomicetos para controle biológico de Ralstonia solanacearum e Erwinia carotovora. 1998. 114p. Dissertação (Mestrado) - Universidade Federal do Rio de Janeiro, Seropédica.

HUSSEY, R.S.; BARKER, K.R. A comparison of methods for collecting inocula of Meloidogyne spp. including a new technique. Plant Disease Reporter, v.57, p.1025-1028, 1973.

INBAR, E.; GREEN, S.J.; HADAR, Y.; MINZ, D. Competing factors of compost concentration and proximity to root affect the distribuition of streptomycetes. Microbial Ecology, v.50, p.73-81, 2005.

JONATHAN, E.L.; BARKER, K.R.; ABDEL-ALIM, F.F.; VRAIN, T.C.; DICKSON, D.W. Biological control of Meloidogyne incognita on tomato and banana with rhizobacteria actinomycetes, and Pasteuria penetrans. Nematropica, v.30, p.231-240, 2000.

KRECHEL, A.; FAUPEL, A.; HALLMANN, J.; ULRICH, A.; BERG, G. Potato-associated bacteria and their antagonistic potential towards plant-pathogenic fungi and the plant-parasitic nematode Meloidogyne incognita (Kofoid \& White) Chitwood. Canadian Journal of Microbiology, v.48, p.772-786, 2002.

LOPES, C.A.; SANTOS, J.R.M. Doenças do tomateiro. Brasília: Embrapa-SPI, 1994. 67p.

MELO, I.S. Agentes microbianos de controle de fungos fitopatogênicos. In: MELO, I.S.; AZEVEDO, J.L. Controle biológico. Jaguariúna: Embrapa-CNPMA, 1998. p.17-67.

MILLER, P.M.; SANDS, D.C. Effects of hydrolytic enzymes on plant-parasitic nematodes. Journal of Nematology, v.9, p.192-197, 1977. 
NAVES, R.L.; CAMPOS, V.P.; SOUZA, R.M. Filtrados de culturas bacterianas endofíticas na motilidade, mortalidade e eclosão de juvenis de segundo estágio de Meloidogyne javanica. Fitopatologia Brasileira, v.29, p.384-388, 2004.

PARK, J.O.; EL-TARABILY, K.A.; GHISALBERTI, E.L.; SIVASITHAMPARAM, K. Pathogenesis of Streptoverticillium albireticuli on Caenorhabditis elegans and its antagonism to soilborne fungal pathogens. Letters in Applied Microbiology, v.35, p.361-365, 2002.

PORTER, J.N.; WILHELM, J.J.; TRESNER, H.D. Method for the preferential isolation of actinomycetes from soils. Applied Microbiology, v.8, p.174-178, 1960.

RENWICK, A.; CAMPBELL, R.; COE, S. Assessment of in vivo screening systems for potencial biocontrol agents o Gaeumannomyces graminis. Plant Pathology, v.40, p.524-532, 1991.
SAMAC, D.A.; KINKEL, L.L. Suppression of the root-lesion nematode (Pratylenchus penetrans) in alfafa (Medicago sativa) by Streptomyces spp. Plant and Soil, v.235, p.35-44, 2001.

SIERRA, S.A. Simple method for detection of lipolytic activity of microorgasnisms and some observations on the influence of the contact between cells and fatty substrates. Antonie van Leeuwenhoek, v.23, p.15-22, 1957.

SOARES, A.C.F.; SOUSA, C. da S.; PEREZ, J.O.; GARRIDO, M. da S. Produção de inóculo de Streptomyces sp. em arroz autoclavado. Fitopatologia Brasileira, v.30, p.66, 2005.

TAYLOR, A.L.; SASSER, J.N. Identification and control of rootknot nematodes (Meloidogyne spp.). Raleigh: North Carolina State University, 1978. 111p.

WALKER, J.T.; SPECHT, C.H.; BEKKER, J.F. Nematicidal activity to Pratylenchus penetrans by culture fluids from actinomycetes and bacteria. Canadian Journal of Microbiology, v.12, p.347-351, 1966. 